\title{
LINGUAGENS CONTEXTO E INTERDISCIPLINARIDADE NO ENSINO indice RURAL
}

\author{
Irene Fernandes dos Santos
}

Vinculado ao Programa de Extensão "Novas Propostas Para o Desenvolvimento da Linguagem em $1^{\circ}$ e $2^{\circ}$ Graus", do Centro de Artes e Letras/UFSM, formou-se, a partir do $2^{\circ}$ semestre de 1997, o GEP "Contexto e Interdisciplinaridade no Ensino Rural" (GEPCIER). Contando inicialmente com doze participantes, esse número ampliouse em 1998, sendo em sua maioria professores de diferentes disciplinas atuando em escolas-núcleos rurais, além de acadêmicos da UFSM.

A formação do grupo deu-se pela necessidade de uma melhor instrumentação técnico-científica e político-pedagógica por parte desses professores, frente aos novos desafios impostos à educação escolar pelas grandes transformações do mundo contemporâneo, bem como em razão da reordenação da educação brasileira, decorrente da implantação da nova LDB. O principal objetivo do GEPCIER é, portanto, oportunizar aos seus integrantes um maior aprofundamento teórico e melhor compreensão da realidade rural, visando à elaboração de uma proposta de currículo contextualizado e interdisciplinar para o ensino fundamental em escolas desse meio.

Os grandes avanços da ciência e da tecnologia apresentam-se, hoje, como mais uma das grandes marcas de desigualdade que fragmentam o mundo contemporâneo, explicitando uma situação de descompasso da sociedade rural em relação às possibilidades científicas e tecnológicas já amplamente dominados pelas sociedades urbanas e cujas condições de acesso têm sido pouco favorecidas às comunidades periféricas e rurais.

Observa-se, porém, que os efeitos desse " progresso social urbano" vêm se projetando de forma anômala junto aos grupos mais refratários às mudanças, como é o caso da sociedade rural, alicerçada em padrões mais rígidos de comportamentos. Oferecendo resistência ou acentuando seu estado de perplexidade perante as inovações, a população do campo vê-se, de qualquer modo, bruscamente afetada pelo fenômeno da globalização econômica e cultural. Ao interferir em todas as áreas da vida humana, principalmente através da ação invasiva dos meios de comunicação, a globalização provoca um impacto bastante negativo junto às culturas específicas, desfigurando-as. Esse efeito de descaracterização ético-cultural dos rurícolas, ao lhes impor novos valores e costumes, ao lado da dominação econômica das cidades sobre o campo, apresenta-se como uma forma aviltante de desenraizamento, fenômeno esse que, segundo WEIL (1979: 348), 
torna-se mais violento quando "o conquistador permanece estranho ao território de que se apoderou, (manifestando-se como) uma doença quase mortal para as populações submetidas".

Todo esse processo precisa ser melhor percebido e repensado, sobretudo no âmbito das instituições escolares, em geral pouco preparadas para um posicionamento mais lúcido frente às interferências desse fenômeno no plano educacional. A escola rural, em função de sua estrutura e currículos quase sempre padronizados e moldados sob os contornos de um modo urbano de pensar, de sentir e de agir e, por outro lado, baseando-se em referenciais pedagógicos herdados do passado, que sedimentam práticas obsoletas, sente-se insegura perante uma crucial "encruzilhada": aceitar ou recusar as transformações que lhe são propostas, ou mesmo impostas? Em qualquer um desses casos, a escola é obrigada a tomar uma posição, seja repensando criticamente o seu currículo para compatibilizá-lo às novas exigências, seja ignorando-as e, nesse caso, correndo o risco de reforçar sua função quase sempre reprodutora de conhecimentos, já não condizente com as solicitações do mundo atual.

É consenso, portanto, que as escolas, em especial as rurais, necessitam sofrer uma profunda reformulação de seus propósitos e de seus métodos, face aos novos paradigmas da ética, da ciência e da tecnologia. Entende-se que o preparo qualificado dos educandos, para interagirem efetivamente e de forma crítico-reflexiva, num mundo em acelerado processo de globalização, implica a construção de novas posturas e de novas ações, sem perder de vista o seu enraizamento sociocultural e o respeito aos valores que são inerentes aos grupos humanos específicos, como ainda se configuram a maior parte das comunidades rurais.

Por sua vez, o quadro docente, que atua na maioria das escolas rurais, a exemplo dos que compõem os demais tipos de escolas, é ele próprio, quase sempre, produto de um ensino conteudístico, fragmentador e desconectado da realidade social. De um modo geral, a formação pedagógica oferecida pelas agências formadoras do magistério pouco os capacita para uma ação interdisciplinar, imprescindível, hoje, para um ensino contextualizado. Em razão disso, grandes são as dificuldades e as limitações docentes para a tomada de decisões que, ao mesmo tempo, direcionem as práticas educativas ao encontro das necessidades e peculiaridades dos diferentes ambientes culturais e atentem para os reclamos da sociedade global.

Que tipo de educação a escola rural deve oferecer, quais conteúdos devem ser priorizados e quais procedimentos metodológicos devem ser adotados, são algumas questões que ainda precisam ser melhor debatidas e definidas para a busca da identidade do ensino fundamental em contextos rurais. Tais questões só podem vir a ser 
melhor esclarecidas a partir de um estudo das relações intervenientes na educação escolar. Enquanto categoria social, a educação atrelase indissociavelmente às análises sócio-históricas de cunho micro e macrossocial , tarefa que cada vez mais se complexifica, considerando-se o permanente estado de mutação característico da nossa contemporaneidade.

Ao considerar essa problemática, o GEPCIER justifica-se pela urgência da abordagem dessas questões, em seu intuito de subsidiar as escolas rurais para uma resposta adequada à tarefa que lhes propõe a nova legislação educacional do país, quando determina uma redefinição das diretrizes curriculares em todas as instâncias do sistema educativo.

Desenvolvendo encontros quinzenais, nosso grupo, desde seu início, dedica-se ao estudo de alguns temas básicos, tais como: sociedade e cultura rural; educação, linguagem e cidadania; e práticas interdisciplinares. Procurando contemplar essas três linhas temáticas, foi elaborado, a partir de 1998, um projeto de pesquisa, denominado "Um currículo contextualizado e interdisciplinar para a escola rural: desenvolvendo a linguagem e construindo a cidadania", com recursos para custeio, incluindo o pagamento de uma bolsista. O referido projeto vem gerando, além dos estudos teóricos já referidos, atividades de pesquisa e práticas interdisciplinares nas escolasnúcleo abrangidas. Nessas atividades, procura-se dar ênfase ao resgate histórico-cultural das comunidades, buscando, através do fortalecimento dos processos participativos e do desenvolvimento da linguagem, a identidade e autonomia discursiva do homem rural, com vistas à construção da sua cidadania.

Essa proposta alicerça-se nos pressupostos de uma educação rural democrático- transformadora, que atribui à escola um papel de mediação entre a cultura e os saberes próprios do homem rural. Esse saber popular deve ser pedagogicamente valorizado, resgatado e preservado em seus valores essenciais e ampliado pelo confronto e/ou articulação ao conhecimento técnico-científico universalizado, de forma a possibilitar um desenvolvimento rural de natureza endógena, baseado na autonomia dos sujeitos e direcionado aos objetivos de realização pessoal e coletiva, através de práticas emancipatórias típicas da cidadania (SANTOS, 1993).

Pelo fato de comportarem os diversos conceitos-chaves necessários à elaboração da proposta lançada por nosso grupo e cujas relações precisam ser compreendidas a partir da concepção de educação rural acima definida, elegeram-se dois eixos teóricos referenciais: a contextualidade e a interdisciplinaridade.

Em relação à primeira, tem-se como pressuposto que um fato educacional, como todo o fenômeno social, não se processa de forma desvinculada do contexto sócio-histórico e que sua identidade só se 
forma e se fortalece a partir da explicitação de suas relações com o todo, num confronto entre o particular e o universal. Entende-se, portanto, que todas as reflexões, ações e produções do grupo devem ocorrer à luz dessa necessária inserção e/ou articulação.

Os conceitos-chaves de uma proposta de currículo contextualizado revitalizam-se através de imagens próprias da educação popular freireana, como a da "leitura de mundo", que deve preceder a própria leitura da palavra (FREIRE,1986:22). Essa leitura de mundo, em seu sentido simbólico, expressa uma estreita relação texto-contexto, que deve constituir-se num dos fundamentos de um ensino rural sob o prisma da contextualidade.

Por exemplo, ao considerar a relação
trabalho/cultura/educação, torna-se
"importante lembrar que a prática produtiva e
política (trabalho) são as fontes básicas da
produção do conhecimento social (cultura). É com
base nesse saber que os camponeses têm
transitado aos descendentes sua atividade
produtiva, os que têm ensinado a interpretar e viver
sua realidade e a exercerem suas capacidades
criativas e e organizativas"(educação).
(DAMASCENO, 1993:57)

No processo educativo de inserção social da criança e do jovem rural, a importância da linguagem, em todas as suas formas de expressão, acentua-se como mecanismo de comunicação humana, na medida em que se constitui elemento fulcral da expressão da cultura, do entendimento entre os homens e, portanto, de socialização e de participação, esta constituindo-se como caminho e expressão da cidadania. (DEMO,1990)

Bordenave, ao abordar várias questões pertinentes à comunicação rural, alerta para os tipos de pedagogia utilizada para essa comunicação nos programas de extensão rural. A primeira opção, a partir de um modelo difusionista ou mero transferidor de tecnologia, seria o da "transmissão ou transferência"; outra opção séria a da "modelagem de comportamento "; por fim, haveria o modelo de "organização e participação", pelo qual "as funções da comunicação rural adquirem sua máxima expressão de diálogo e de participação nesta perspectiva transformadora (... ) que retoma sua verdadeira identidade como expressão da cultura popular..."(BORDENAVE, 1988:43)

Quanto à interdisciplinariedade, CREMA (1989), numa visão holística da ciência, apregoa a necessidade de métodos voltados para a reunificação da ciência, fragmentada a partir da instauração do racionalismo cartesiano. Nessa linha de pensamento, filiada a uma filosofia centrada nos sujeitos, a interdisciplinaridade coloca-se como 
forma adequada de buscar a construção do conhecimento e "impõese não só como forma de compreender e modificar o mundo, como também por uma exigência interna das ciências, que buscam 0 restabelecimento da unidade perdida do Saber" (FAZENDA, 1992: 53).

Sem abrir mão das especifidades do conhecimento, a interdisciplinaridade possível é aquela considerada enquanto "transposição" ou "deslocamento de um contexto para outro ". Nesse sentido,

\begin{abstract}
"a interdisciplinaridade não poderá jamais consistir em reduzir as ciências a um denominador comum, que acaba destruindo as especificidades de cada uma, de um lado, e dissolve cada vez mais os conteúdos vivos em formalizações vazias, que nada explicam, podendo pelo contrário, transformar-se em estratégias de exclusão e de domínio absoluto. Pelo contrário deverá ser um mediador que possibilita a compreensão da ciência, além de formas de cooperação a um nível bem mais crítico e criativo entre os cientistas". (ETGES, op.cit: 73)
\end{abstract}

No nosso trabalho, portanto, a partir de pressupostos de uma dialética superadora de visões antagônicas, tentamos fazer a mediação entre ambos os conceitos. Busca-se, desse modo entender e construir uma interdisciplinaridade que não se constitua apenas procedimento metodológico mas atitude que, imbricada ao conceito de contextualidade, possa vir a orientar todo o desenvolvimento de uma proposta educacional para o meio rural. Procura-se, à luz desse entendimento, considerar as múltiplas dimensões do educando e da realidade social, histórica e cultural das comunidades rurais. tendo no trato de diferentes linguagens (discurso urbano e discurso rural), não o conflito entre elas (que resulta quase sempre em supremacia de uma em detrimento do outra), mas a prática de uma interdiscursividade construtora de discursos emancipatórios para o homem rural.

BIBLIOGRAFIA:

BORDENAVE, Juan D. O que é comunicação rural? São Paulo:Brasiliense, 1988.

CREMA, Roberto. Introdução à Visão Holística. São Paulo, Summus, 1989.

DAMASCENO, Maria N. A construção do saber social pelo camponês na sua prática produtiva e política In: THERRIEN \& DAMASCENO (Coords.) Educação e Escola no Campo. Campinas: Papirus, 1993: 53-73.

DEMO, Pedro. Participação é Conquista: noções de política social participativa. São Paulo: Cortez Editores, 1990.

ETGES, Norberto. Ciência, Interdisciplinaridade e Educação. In: 
JANTESCH \& BIANCHETTI (orgs.) Interdisciplinaridade. Para além da filosofia do sujeito. Petrópolis:Vozes, 1995: 51-84

FAZENDA, Ivani C.A. Integração e Interdisciplinaridade no Ensino Brasileiro. Efetividade ou Ideologia. São Paulo: Edições Loyola, 1992.

FREIRE, Paulo. A importância do ato de ler. São Paulo, Cortez Editora, 1986.

SANTOS, Irene F. Tendência democrático-transformadora. In: EscolaNúcleo como alternativa para a Educação Rural: análise sóciohistórica de umaexperiência pedagógica no município de Santa Maria-RS. Santa Maria: UFSM/CE, 1993 : 44-47 (dissertação de mestrado).

WEIL, Simone. O desenraizamento. In: A condição operária e outros estudos sobre a opressão. Rio de Janeiro: Paz e Terra, 1979.

[índice ] [ resumo ] 